\title{
Atypical Pressure Ulcer as Cellulitis Mimic
}

\author{
Ngoc-Bao Le, $B A^{1,2}$ and Josué Zapata, MD, MBA ${ }^{3}$ \\ 'UCSF School of Medicine, San Francisco, CA, USA; ${ }^{2}$ Department of Medicine, University of California, San Francisco, CA, USA; ${ }^{3}$ San Francisco \\ Veterans Affairs Health Care System, Department of Veterans Affairs, San Francisco, CA, USA.
}

KEY WORDS: bean bag; clinical image; dermatology; injury; pressure ulcer.

J Gen Intern Med 33(10): 1816

DOI: $10.1007 / \mathrm{s} 11606-018-4550-3$

(c) Society of General Internal Medicine 2018

\begin{abstract}
A 78-year-old man was treated for cellulitis after presenting with an area of erythema and slight ulceration on his thigh after being shot by a bean bag gun. One week later, he represented due to progression of his wound (Fig. 1). Cultures returned sterile and the patient's condition did not improve despite antibiotics, prompting dermatology consultation and skin biopsy. Pathology subsequently revealed pressure ulceration.
\end{abstract}

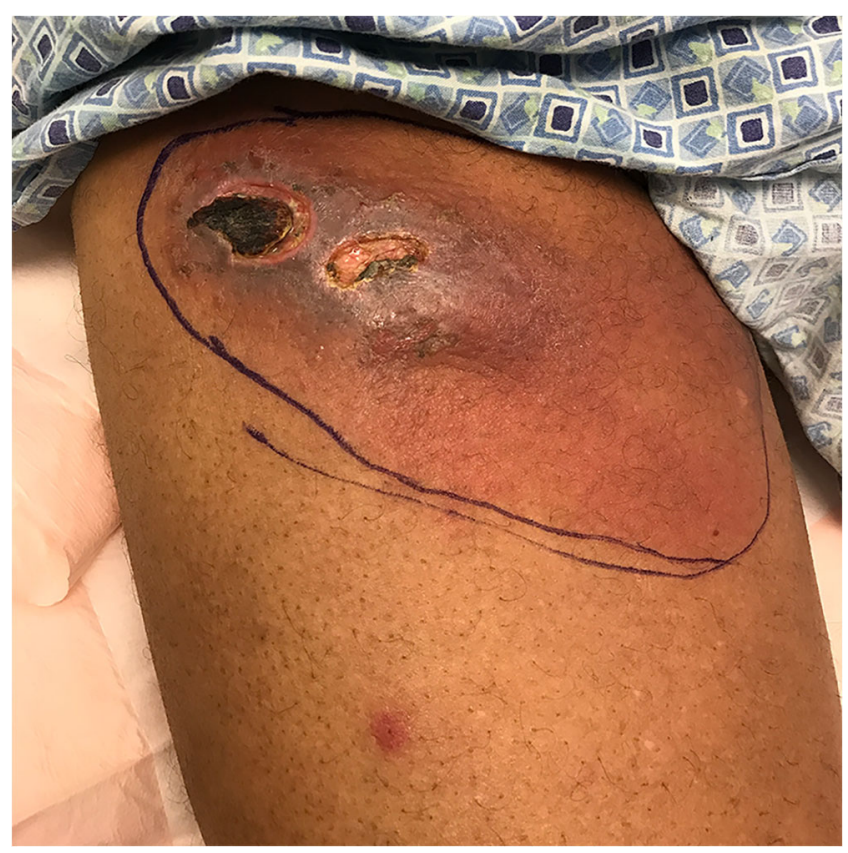

Figure $114 \times 7 \mathrm{~cm}$ well-demarcated, erythematous, warm, and indurated area on patient's right anterior thigh with two round ulcerations (each about $3 \times 2 \mathrm{~cm}$ ) draining serous fluid.
Pressure ulcers are commonly caused by sustained low-grade pressure and frequently seen on bony prominences in immobile individuals. ${ }^{1}$ However, they can also develop from momentary exposure to extreme pressure such as that generated by a bean bag projectile, which can deliver a force comparable to a baseball line drive. ${ }^{2,3}$

The clinical presentation of pressure-induced injury can mimic cellulitis, displaying erythema and warmth. Deeper layers of soft tissue are more susceptible to pressure-induced injury than superficial layers. ${ }^{1}$ Therefore, high-pressure injuries can initially present with little or no superficial ulceration before eventually manifesting at the surface. Though pressure ulcers are typically encountered in a different clinical context, their occurrence in the setting of acute trauma highlights the key common pathogenic principles driving this familiar condition, including interface pressure, shear stress, and resultant tissue ischemia and necrosis. ${ }^{4}$

Corresponding Author: Ngoc-Bao Le, BA; UCSF School of Medicine, San Francisco, CA, USA (e-mail: bao.le@ucsf.edu).

Compliance with Ethical Standards:

Conflict of Interest: The authors declare that they have no conflicts of interest.

Ethics/Institutional Review Board Approval: Not applicable to this manuscript.

\section{REFERENCES}

1. Bauer J, Phillips LG. MOC-PSSM CME article: Pressure sores. Plast Reconstr Surg 2008;121(1 Suppl):1-10.

2. Grange JT, Kozak R, Gonzalez J. Penetrating injury from a less-lethal bean bag gun. J Trauma 2002;52(3):576-8.

3. de Brito $\mathbf{D}$, Challoner KR, Sehgal A, et al. The injury pattern of a new law enforcement weapon: the police bean bag. Ann Emerg Med 2001;38(4):383-90.

4. Grey JE, Harding KG, Enoch S. Pressure ulcers. BMJ. 2006;332(7539):472-475.

Received January 12, 2018

Revised March 20, 2018

Accepted June 28, 2018

Published online July 10, 2018 